\title{
EDITORIAL
}

\section{That Others May Live: Lessons Learned From the 2011 Denali Climbing Season}

As I pack for a return to Alaska in a week's time, I am forced to reflect on the eventful climbing season prior. It was not the number of climbers $(1,232)$ or the summit success rate $(56 \%)$ that made 2011 of note. It was the number of serious accidents (15) and resulting fatalities (9, second highest in a season, only behind 11 in 1992) that made last year stand out from all others in recent memory. Causes of these deaths included climbing falls (5), unknown (2), icefall (1), and sudden cardiac death (1). Three of these falls occurred on the steep traversing terrain known as the Autobahn at approximately 18200 feet, and the 2 unknown causes were either an avalanche resulting in a fall or a fall while climbing in technical terrain. Consistent with historical data, 5 of the fatalities (61.5\% between 1932 and 2006) occurred while the climber was descending, travel direction for $2(13.5 \%$ between 1932 and 2006) was unknown, and 2 occurred while the climber was in camp. ${ }^{1}$ Each of these tragic accidents serves as sobering and valuable reminders of the risks inherent in mountaineering. (Details of these incidents can be found online in the 2011 Denali Annual Mountaineering Summary.)

"Good judgment comes from bad judgment" was a statement I heard recently from Dr Thomas Russell, former executive director of the American College of Surgeons. I was struck by the truth of this quotation, but even more so by the frightening reality and consequence of its implication. In spite of the plethora of antagonistic examples, decisions will continue to be made in the mountains that have high potential for disaster. Studies have repeatedly shown that it typically is not a single choice but a cascade of poor decisions that lead to an ultimately bad outcome. Regardless, I write this editorial with purposeful and ignorant optimism that these principles needn't be relearned firsthand by anyone in the future.

In the months that have passed since the conclusion of last season, I have fielded countless inquiries pertaining to the specific factors that led to the events of 2011. This line of questioning has prompted thorough contemplation on my behalf. Even still, I am left at times shrugging my shoulders and telling the curious party that I just don't know. Sure, I do have some ideas, but concrete and factual causes, as with many disasters, may never be fully realized. Two of the common themes that I find myself reiterating have been the hostile weather of last season and the lack of preparedness for these adverse conditions. Of course, these are broad generalizations, and undoubtedly individual human factors played a role in each of the accidents.

Some say that Mount McKinley is the coldest peak on earth, and she certainly lived up to that reputation this past summer. Cold temperatures and bare glacial ice dominated the Alaska Range landscape for much of April and May. Early season climbers reported temperatures consistently below zero Fahrenheit, 24 hours a day, through mid May. Perhaps this unrelenting deep freeze ultimately affected the judgment and challenged the technical abilities of the climbers. Whenever traveling in technical terrain, any diminishment in mental capacities and resulting missteps creates the potential for a much higher set of consequences.

Owing to the intense winds and limited snowfall during the winter of 2010/2011, the majority of the upper mountain was completely devoid of snow when the early expeditions began climbing. These conditions led to extremely difficult footing on the standard climbing route and made self-arrest nearly impossible in the event of a fall. Cramponing and self-arrest skills are typically learned on lower angle slopes with sufficient snow underfoot. This is a terrific venue in which to learn but should not represent the culmination of one's tutelage. On these mellow slopes and in deeper snow conditions, much of the arrest is accomplished merely by gravity and friction. When the angle steepens and the terrain becomes icy, I often hear the term "no fall zone" used when commands are passed between teammates. I think this notion represents naïve risk management. Climbers need to maintain a constant awareness of their surroundings and mitigate potential risks should an error occur. If a fall cannot be arrested in the traditional manner, it is incumbent on the climbers to either unrope to prevent pulling additional teammates down the slope or, preferably, place protection (snow pickets, ice screws, and so forth) along the path of travel. 
I agree wholeheartedly with Alaska Mountaineering School owner Colby Coombs when he says, "Denali is a final exam." A lengthy apprenticeship is a mandatory component toward gaining expertise in most pursuits, be it climbing, medicine, or any other discipline. Amazing educators and guides can teach the progression from basic to advanced skills and help the student begin to manage risk on his or her own. It would be absurd to expect a surgical resident to move directly from cyst removal to a Whipple procedure. The same is true in skipping necessary benchmarks along one's development as a self-sufficient wilderness traveler.

My intent here is the furthest from assigning blame or dwelling on the exact circumstances surrounding each accident. Instead, I am invested in promoting safe climbing practices "... that others may live," as the USAF Pararescue motto implies. The Denali Mountaineering Operation is likely the most extensive registration and climber-briefing program in the world. Initially, every climber is screened by resume and, later, upon arrival in Alaska, briefed on the route, current conditions, anticipated technical and medical complications, and park policy specifics. To continue to improve on this exemplary service, we utilize the most current wilderness medical and mountain rescue literature. That allows us to be better able to advise expedition members on problems likely to be encountered and their solution algorithms.

In light of these accidents, the following adages seem poignant as the upcoming climbing season rapidly approaches. These are the lessons I desperately hope will make a difference in the decisions of future expeditions, by furthering Dr Russell's wisdom and allowing the previous judgments of others to assist in the cultivation of their own good judgment. As you venture into the backcountry, events outside of our control will occur. We can attempt to mitigate as much risk as possible but must remain cognizant that completely objective events will unfold regardless. We can be prepared for worstcase scenarios, however. That is best accomplished by pondering potentials during travel and, more importantly, by considering how you and your team will remedy those situations should they occur. Human factors can have very direct and drastic repercussions on our safety, with both our decisions and our indecisions climaxing in disastrous consequence. A key to risk mitigation is familiarity with the decision-making traps to which you are most prone and keenly recognizing when those factors begin to derail your process. Listening to one's intuition and speaking up accordingly are so often reported as missed opportunities by the individual members of parties involved in mishaps. Remaining silent and hoping that events go in your favor is a horrible risk management tool. And above all, if you find yourself doing what others are not, you should have a very good reason.

David Weber, WEMT-P Mountaineering Ranger, Denali National Park Technical Rescue Advisor, Diploma in Mountain Medicine Wilderness Medical Society Salt Lake City, UT

\section{Reference}

1. McIntosh SE, Campbell AD, Dow J, Grissom CK. Mountaineering fatalities on Denali. High Alt Med Biol. 2008;9: 89-95. 